\title{
Presencia del Concejo en lo docente
}

La Europa actual, precisando más, la Europa inmediatamente anterior a la última guerra mundial, era un semillero de centros docentes, primarios y secundarios, que funcionaban bajo el auspicio concejil. Estos centros: colléges, gimnasios, liceos, escuelas de enseñanza industrial y agrícola, de beneficencia docente, saludaban, a través de los siglos, a aquellas famosas escuelas municipales que brotaron a la vida exigente incubadas en el calor y el ejemplo de la Iglesia, principalmente ante la transformación que experimentó la vida civil, económica y social, como consecuencia de un progreso de hechos extraordinarios: las Cruzadas.

Pero los antecedentesı son mucho más remotos; también aquí cabría decir que se pierden en la sombra mal penetrada de los tiempos, aunque tarde en aparecer la línea clara de la diferenciación. La investigación específica no se ha realizado, que sepamos. Cuando tenga lugar esperamos ver descubierta una de las más interesantes ejecutorias municipales. Nos limitamos hoy a recopilar y ordenar algunas referencias dispersas, suficientes, en parte, a justíficar el título de este trabajo.

\section{I.-GReCIA y Roma}

Es Grecia la que alumbra las grandes concepciones, que en cierto modo cabe llamar "modernas", de la vida social, del Estado y de la enseñanza: de la cultura. Pero en la civilización griega hemos de acercarnos a la época de Pericles para localizar, bien definidos, los basamentos imperecederos de su filosofía y hasta de su pedagogía, y, para nuestro objeto, enfrentar- 
nos con la propia concepción del Estado, vinculado a su CiudadEstado.

Y cabe preguntar: ¿La idea de la Ciudad-Estado rechaza a la idea de la Ciudad-Municipio ?... "El proceso de la civilización griega - escribe Rowe- empieza y termina con sus ciudades; ninguna otra nación ha concentrado tan completamente su vida y su pensamiento en el perfeccionamiento de la vida de ciudad». Se caracterizaban por una fuerte autodeterminación; no constituían municipalidades en el sentido moderno de la palabra, comenta Posada. Eran Ciudades-Estados. Pero - precisa Munro- ninguna distinción se advierte en la Grecia antigua entre e! gobierno nacional y el municipal; "los dos se hallaban entrelazados", es decir, coexistían.

En Grecia había, sin embargo, una municipalidad más diferenciada: el demos o municipalidad subsidiaria, que se define: "El demos era una parte determinada del territorio del Estado, era un Ayuntamiento, con el doble carácter de asociación y de división administrativan, donde se satisfacían las fundamentales necesidades de la colectividad y donde el tejido de relaciones era más de neta índole procomunal (Giraud). "No todos los demos tenían igual importancia, pero tenían la misma organización. Cada uno tenía al frente una especie de alcalde electivo, llamado demarca, y varios funcionarios civiles y religiosos; cada uno tenía sus bienes, su presupuesto, sus fiestas. Sus asuntos eran administrados por la totalidad de los ciudadanos del demon (Ibid). La educación había de ser asimismo preocupación del demo; hasta las fiestas revestían, según la ininterrumpida tradición griega, un fondo, una trascendencia educativa; para ellas y en ellas se formaba el joven que era, a la vez que el protagonista, "el discípulo más aventajado".

De las funciones propias de la Ciudad-Estado, ¿ cuántas podríamos escoger para cualificarlas y comprenderlas en un molde o tónica municipalistas ?... Confundidas las dos ideas, se da una prelación nominativa al término Estado, más por convencionalismo exegético o por el rango mismo, universalista y luminoso, de las viejası urbes madres, que por la índole y contenido de la.relación. Urbes en las que su civitas, su polis, se levantarían, 
en la relación de cada hora y en el intercambio ciudadano, humano, como en un grande Municipio, que con vitola de tal se. hallaba presente ofreciendo sus ágoras, gimnasios y palestras, a veces también las soleadas rotondas de extramuros, al augusto ejercicio docente. Cuando la mirada parte de Atenas, vuela y remonta sobre las murallas de la ciudad gloriosa, lleva visión y horizonte de Estado; cuando se concentra intramuros se impregna y colora de Municipio, halla la sede íntima y materna de la municipalidad.

Ahora bien, "el período culminante $-\mathrm{y}$ decisivo- en el proceso o génesis del Municipio, como comunidad de vida, y como. régimen político-administrativo de ésta, una vez incorporada a. más amplia organización, es el de la expansión romana" (Posada). Y Roma como Ciudad, como Municipio - se ha dicho-, no es menos maravillosa que Roma como Imperio. En la amplia esfera autonómica de las ciudades y municipios de Italia y de las provincias, que caracterizaba al gobierno romano, según Mommsen, no podían faltar las instituciones de enseñanza, diversas, auspicio de la municipalidad, cuyos vestigios, todavía operantes, encontraron las legiones romanas en las antiguas ciudades helenizadas, según veremos. Pero es el Imperio, en Roma, el que se preocupa de organizar políticamente, estatalmente, las enseñanzas. Hasta llegar a él, la educación, la instrucción, no es una misión del Estado: "Entre nosotros, la enseñanza no está regulada por las leyes, ni es pública, ni común, ni uniforme para todos", declara Cicerón en su $D e R e p u$ blica (IV, 3).

"Renglón especial del presupuesto de las ciudades lo formaban los gastos consagrados a la instrucción pública y a la educación físicà de sus habitantes, jóvenes o maduros, sobre todo en las ciudades totalmente helenizadas de Oriente. Haber asistido a un curso de instrucción en la palestra o en el gimnasio era el distintivo del hombre educado, frente al bárbaro. En Egipto, por ejemplo, los individuos educados en los gimnasios formaban una clase especial de la población, favorecida con ciertos derechos y privilegios... Muchas inscripciones muestran que las ciudades del Oriente griego no habian olvidado su gloriosn 
pretérito y se afanaban, tanto como antes, y acaso más, en pro. curar a la juventud urbana una buena educación al estilo griego. Esto era muy costoso. Eran precisas grandes sumas para pagar. a los profesores, construir escuelas y campos de deportes y atender a su conservación" (M. Rostovtzeff).

De fundación generalmente imperial, al menos en un principio, pero de atención constante y sostenimiento municipalista, sobresalieron notables centros docentes en la España romana. En ellos se educaron muchos de los grandes genios dados. a Roma: Quintiliano en Calagurris, Marcial en Bílbilis; antes los Séneca frecuentarian alguna famosa escuela de poetas cordobeses... Alberto Samper nos facilita unas interesantes referencias de las escuelas públicas que funcionaban en España durante la dominación de Roma, escuelas que suponían una grave y constante preocupación para los municipia, y que alcanzaron un alto grado de perfeccionamiento y una señaladísima eficácia. El patrón estaba tomado de Grecia, en la que ya vimos que la instrucción pública era atención de la ciudad, del demos, del Municipio: “En los' edificios destinados a la enseñanza, al lado de las casas de estudios se establecían jardines con baños, a fin de que los estudiantes pudieran adiestrarse en losi ejercicios corporales y gimnásticos... A.l frente de cada escuela había un jefe, llamado gymnasiarca, asistido de varios dependientes que se designaban con los nombres de prescheles, antesdioles y luypodidascales, que eran a la vez inspectores de los maestros y de los discípulos, teniendo especialmente por misión coordinar la acción de profesores y regentes. Los prescheles se dedicaban con especialidad a dirigir la educación física, velando al mismo tiempo por la disciplina interior. Había también maestros particulares que se llamaban pedagogos..."

"En el interior de las escuelas se distinguían tres clases de discípulos: los externos o libres, los convictoris o pensionistas, y los alimentarii, que posteriormente se han llamado becarios... Los profesores estaban retribuídos percibiendo la dotación de $\mathbf{1 0 . 0 0 0}$ dracmas (unas $\mathbf{7 . 0 0 0}$ pesetas), y tenian determinadas inmunidades, como exención para sí y su familia de toda carga pública, alojamiento militar, tutela, etc.) (Samper). Estos maes- 
tros eran llamados a desempeñar los más altos cargos de la magistratura municipal. Con frecuencia, en las palestras, donde tenían lugar los ejercicios físicos de exhibición y las competiciones deportivas, ocupaban los puestos de honor los primeros. magistrados de la ciudad, bajo cuyas togas respiraban maestros venerables.

Todo lo social en las provincias de Roma era peculiar de las ciudades, de tan variada condición y trato, encarnadoras de municipios pujantes, que pudieron sostener durante muchos siglos al más dilatado y soberbio imperio de la Antigüedad. Desde las remotísimas escuelas triviales, que surgieron como impulsadas por un hálito concejil cuando el Estado, la República, no se preocupaba de regular la enseñanza, hasta la más alta cumbre y esplendor del Imperio; lo municipal, en Roma, tutelaba lo docente y lo docente era en las ciudades romanas una función social de primerísimo orden.

\section{II.-EDAD MEDIA}

\section{a) El Prelado y el Concejo.}

Subsiste el Municipio impregnándose de savia germánica, arrastrando aún el viejo lastre indígena de los primitivos concilios populares; pero la época visigótica es turbulenta y crítica, llena de ambición y pasiones primarias que se precipitan por los territorios de conquista buscando subconscientemente originales y definitivas afirmaciones. Los centros culturales heredados de Roma desaparecen bruscamente y las ciudades se convierten en meros recintos del nuevo y rudo apresto militar. Perdura, fortaleciéndose con cada evento, el espíritu del Cristianismo, que alimenta en los templos y monasterios, en el cenobio o el eremo, el quehacer docente y anuncia el triunfo de la más completa de las unidades sociales: la religiosa. La época gótica, si turbia y azotada intestinamente, es también, al fin y al cabo, fase decisiva en el gran proceso ibérico, con expresión de verdadera natura naturans, cualidad y privilegio formidable 
que nunca abandonará ya a España, madre de pueblos y civilizaciones, con amor en tal extremo de afecto, que como si iesucitase la propia Atlántida, descubrió y evangelizó el continente americano y se lo puso de firmísimo soporte a Europa, para que reclinara en aquél su vejez y su orgullo y pudiese alentar la gozosa esperanza de que la civilización de Occidente contaba, para su continuidad, con un nuevo e inmenso campo de expansión.

De la época visigótica queda noticia de una escuela primaria establecida en la Comunidad Cauliana, cerca de Mérida, de inconfundible signo concejil.

Pero las más vigorosas raíces de la tradición municipalista en lo docente prenden en los senos fecundos de la Edad Media, a la sombra y bajo el ejemplo de la Iglesia. El Prelado y el Concejo: he aquí los dos puntales de la enseñanza popular en el más grandioso monumento jurídico del Medioevo. La Partida II, título XXXI, del Código Alfonsino, fundamenta, como sigue, la trascendente cuestión: "E porque de los homes sabios, los homes y las tierras e los reynos se aprovechan e se guardan, e se guian bien por el consejo dellos, porende queremos en la fin desta partida fablar de los estudios e de los maestros e de los escolares que se travajan de amostrar e de aprender los saberes...n. En la Ley primera define los, estudios, señala sus clases y a quienes incumbe establecerlos: "Estudio es ayuntamiento de maestros e de escolares que es fecho en algun lugar con voluntad e entendimiento de aprender los saberes. E son dos maneras del. La una que dizen estudio general... E otro es a que dizen estudio pariticular que quiere tanto dezir como quando algún maestro muestra en alguna villa apartadamente a pocos escolares. E a tal como este pueden mandar facer perlados o concejo de algun lugar»... El pensamiento del sabio legislador se ha fija- do, al trazar la disposición transcrita, no en los núcleos de población importantes, sinó en los apartados, en las villas y aldeas de sus reinos, para los que previene el bien necesario de la enseñanza. Pero la Ley Alfonsina no crea una realidad, se limita a recoger una tradición y un ambiente. La vida exige, presionante, una profunda renovación y hasta remoción de valores e ins- 
tituciones. Toda la Edad Media es un incomparable procesofundacional: lo había sentido así, vivamente, el Santo Rey Fernando, que inició y acometió la labor. Y, por él, tiene lugar en. España, norte siempre de las tareas del espíritu, un primer renacimiento cultural que hará propicio y fácil un maravilloso siglo de oro. Para la espléndida cosecha institucional docente se cuenta con el Concejo, célula vitalísima, de cuyo vigor depende el florecimiento de los Estados.

Todo el título XXXI de la Partida II gira en torno a los. estudios, con curiosidades y prevenciones muy sabias. En la Ley segunda se habla del emplazamiento que debe tener la escuela y.de las condiciones que ha de reunir el lugar: "De buen aire - se dice- e de fermosas salidas, porque los maestros que muestran los saberes e los escolares que los aprenden vivan sanos en él e puedan folgar e recibir placer quando se levanten cansados: del estudion. La recomendación resalta su propio y neto sentido pedagógico, en el que se inspirarán todos los grandes maestros: De Feltre, con su Casa Giocosa del lago de Mantua; Thomas Arnold en $R u g b y$; Edmundo Demolins, con su L'Ecole des Roches en la campiña de Verneuil; Rabindranath Tagore, en sur Shantinikitan u Hogar feliz de Bolpur... Rebosa el amor a la naturaleza y se pone en estrecha relación al maestro y el estudiante con el campo, los aires puros, los maravillosos paisajes, los fenómenos naturales en fin, donde se estudia una permanente y grandiosa lección, que no ofrecerán jamás los laberintos ciudadanos. Hay, en la ley imperial, como un fondo ruraI encantador, reflejo del que ofrecen tantas y tantas comunidades concejiles, asientos incomparables para acoger, con silencio y calor propicios, la vocación docente; refugios que atrajeron, cuando los hombres iban más despacio y las cosas se ponían siempre por su orden "una detrás de otra", a los más grandes. maestros y educadores.

Maternalmente, la ley se detiene ahora en cuestión tan delicada como la del alojamiento de los escolares, y previene "que la villa sea abondada de pan e de vino e de buenas posadas en que puedan morar e pasar su tiempo sin gran costan... Manda que los ciudadanos del iugar donde se haga el estudio "deber 
mucho guardar e honrar a los maestros e a los escolares e a todas sus cosas", con otorgamiento de especial salvoconducto para que "los maestros e los escolares e sus mensajeros e todas sus cosas sean seguras e atreguadas, en viniendo a las escuelas, en estando en ellas, o yendo a sus tierras".

Recoge y funde en norma el espíritu gremial, de asociación o de comunidad, tan característico de la Edad Media. Así la Ley sexta habla de cómo los maestros y escolares pueden hacer. ayuntamientos y hermandad entre sí, e incluso escoger uno que los juzgue y castigue; pero manda rigurosamente "que se guarden en todas guisas" de levantar bandos ni peleas con los hombres de los lugares donde estuvieren, ni entre sí mismos, no haciendo deshonra ni tuerto a ninguno, y que no anden de noche "más que finquen sosegados en sus posadas", estudiando y aprendiendo y haciendo "vida honesta y buena"... Después de garantizar la retribución de los maestros, de prevenir los casos de enfermedad y muerte, de exencionar e inmunizar a los educadores contra pechos y complicaciones que no deben inquietarles en bien del ejercicio de su augusta función, esbozando un notable capitulo de Derecho Social, curiosamente progresivo para aquellos tiempos, la Ley séptima reconoce un fuero especial para profesores y alumnos, jurisdicción propia, y, por antonomasia, auténtico privilegio escolar. El estudiante puede negarse a responder a toda demanda si no es ante su maestro o ante el Obispo; puede elegir, como juez, al mismo Obispo o al propio del Fuero, según quiera...

Un régimen especial de garantías y exenciones ha protegido siempre a las instituciones docentes y a sus hijos; en esa tradición purísima y sabia cabría fundamentar ahora una tesis, cuyo desarrollo debieran permitir ya las sociedades civilizadas: ahorrar al educador, al maestro, toda inquietud personal por el primum vivere. Meta que los Estados debieran coronar con decisión. La consecuencia sería dúplice: maestros verdaderos, maestros completos, $y$, por su fruto, tal vez en breves lustros esa reconstrucción del hombre, de la misma sociedad, que anhela Alexis Carrel. Pero junto a la ilusión el más crudo y sangriento de los desengaños: ayer, hoy quizá, acaso mañana, los 
tiempos contemplàrán patéticamente cómo los hijos de ulas luces» adiestrados por su madrastra hollarán -arma o procacidad- las sagradas mansiones donde se muestran los saberes, para las que una tradición lenta y multisecular fué trabajando el camino de su perfección.

Los estudios particulares, que fundan el Prelado o el Concejo, fueron a su vez de dos clases, de primera y segunda enseñanza, llamándose a éstos Escuelas o Estudios de. Arte. Se extendieron profusamente "disputándose reyes, prelados y concejos el honor de fundarlos labrándose para ellos notables edificios". Raimundo Lulio los creó en Mallorca en 1280, siendo reformados y aumentados en 1478. Jaime I los había establecido en Valencia en 1245, levantándose después diversas Escuelas de Gramática y Artes, que por un acuerdo del Concejo de la ciudad,

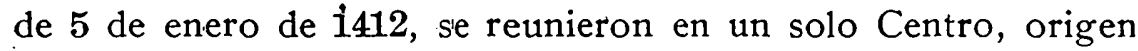
de la Universidad actual (Vives y Liern). Murcia los abrió en 1310. Muchos de los que un día llegaron a ser Estudios generales o Universidades habían comenzado siendo Estudios de Artes, en numerosos casos concejiles... "Pocas villas dejaron de tener su Estudio público, y no sólọ de Gramática sino de Filosofía, que era la preparación para ingresar en las Universidades"... Pedro Fernández de Navarrete, en su libro Conservación de Monarquías, impreso en 1626, fija en "más de cuatro mil los Estudios de Gramática existentes en España", y lo mismo confirma Lafuente en su Historia de. las Universidades. Entonces tenía España una población no superior a un tercio de la actual. Frodigaban el saber al pie de veinticinco universidades... Se comprende, por muchas razones, el que Taine haya podido exclamar: "Hubo un momento extraño y superior de la especie humana: la España del 1500 al 1700".

\section{b) Escuelas municipales y gremiales.}

Como seguro eslabón entre la Iglesia y el Estado, en lo que a enseñanza s€ refiere, actuará el Municipio y junto a él el Gremio. Las escuelas propias de uno y otro enlazan con las monásticas, parroquiales y catedralicias y harán posible un mag- 
no florecimiento de Colegios mayores y Universidades. Surgieron las escuelas municipales como un fruto necesario de la sociedad que se complicaba, de la vida social que crecía. Las profundas transformaciones económicas de los siglos xII y xIII, consecuencia de las Cruzadas y de los intercambios que de éstas se derivan, acrecen la importancia de numerosas ciudades. Junto a la propiedad territorial, hasta entonces estimada como la única riqueza, aparece el capital circulante a modo de unueva potencia” económico-social. Lógicamente se suscitan, con viva palpitación, nuevas inquietudes espirituales, y por ello se observa cómo en laś ciudades, singularmente entre los habitantes de los barrios de nueva creación, se siente la necesidad de poseer en sus circunscripciones escuelas propias, pues resultaba demasiado largo el camino que conducía a la Escuela catedral.

En un principio provee los cargos de las nuevas escuelas, creadas y sostenidas por el Concejo, el director de la Escuela catedralicia. Clérigos documentados en la experiencia docente las regentan. Andando el tiempo, en el siglo xv, unánimemente ya, los cargos son provistos por los municipios, quienes aprueban los reglamentos de las escuelas y ejercen la inspección escolar. "En estas escuelas municipales percibíanse siempre honorarios, aunque proporcionados a los recursos económicos de los padres. Cuando lo recaudado no subvenía a las necesidades del maestro, el Concejo había de mejorar dicha suma... Tam-. bién era misión municipal la conservación y sostenimiento de los edificios escolares" (Messer).

Comprendía la enseñanza el estudio del Jatín, y en muchos casos conocimientos en cuantía suficiente para calificarlos de secundarios y aun de superiores. Se desborda, ante el ejemplo y protección de los concejos, la iniciativa privada, palanca inapreciable en el progreso de la cultura. Alcánzan no sólo extraordinaria difusión sino considerable perfeccionamiento, y es el Municipio entonces la viva encarnación del más genuino poder civil que se preocupa de $\tan$ relevante inquietud social. Numerosas fundaciones particulares imprimen un ritmo seguro en la marcha de la gran cuestión y de ellas, que el Concejo estimuló y favoreció, se informará un día el propio Concejo. como ocu- 
rre con las llamadas scholae claecularin, de preceptores privados, que se conocerán también con el nombre de umaestros de escuela" o "escribanos de silla", cuya misión, eminentemente práctica, se reducía a la lectura, escritura y cálculo elemental, constituyendo el tipo de enseñanzas que se estimó más adecuado para introducirse rápidamente en las campiñas y aldeas. “A fines de la Edad Media hallamos. escuelas no sólo en las ciudades, sino tambien en los campos, latinas y nacionales (en las que se enseñaba el y con el idioma nacional), dirigidas unas veces por clérigos, otras por cantores y sacristanes, y, en ocasiones, por maestros ambulantes o estudiantes errabundos" (Ibid).

En España quedan aún - merced a la tradicional indigencia del Estado, de siglos a esta parte- numerosas supervivencias de estas escuelas, sin sede adecuada, regentadas por maestros ambulantes. Tales, por vía de ejemplo, las que funcionan en muchos pueblos de Ibias, Concejo de Cangas del Narcea, Sierra y Somiedo (en Asturias), o los pueblos de Fornela (de León), etcétera. A estos lugares, misérrimas aldeas por lo general, incomunicadas, bloqueadas meses y meses por duros temporales de nieves, se allegan maestros de afición, sin título alguno, en algún caso estudiantes pobres que se preparan privadamente y se examinan "por libres"; que "ajustan" sus estipendios con el Concejo de la entidad local, su Junta, o bien directamente con los padres de los escolares, incluyendo siempre la alimentación, lavado y cosido de ropas, servicios que se prestan por turno o velanda vecinal. Explican las lecciones en alguna dependencia auxiliar de la Iglesia, local de concejo, o bien en algún portal, rudimentariamente acondicionados con unos escaños o asientos primitivos... Y es tradición, lamentable de veras, el que en alguno de estos concejos, al lado de los reales de sus ferias de otoño, tuviese lugar un a modo de "mercado de maestros", al que éstos concurrian "ofreciendo sus saberes y disposiciones", que exponían, juntamente con sus pretensiones, a los representantes de las aldeas portadores del encargo de "alquilar maestro". Con frecuencia se entablaban regateos tan prolongados y pintorescos como los que se acostumbran en las transacciones de ganado - chalaneo- en las ferias españolas... Sátira viva y 
sangrante contra la desaprensión de los políticos, que tantas veces, "con tantas penalidades, ofreciendo el oro y el moro", recorrían estos terruños proscritos pidiendo los votos de los aldeanos para el propio encumbramiento. Pero la realidad, a pesar de su feo exterior, acredita una verdad profunda, humana, de excelente signo optimista: el anhelo de redención, que aun las mentes más ignorantes y despobladas intuyen por la vía de la enseñanza. El fruto, poco.o mucho, que por sí mismas consiguen estas apartadas y minúsculas aldeas en tan importante aspecto de la vida, lo deben únicamente a sus concejos, tan pobres como la miseria, o a una acción colectiva de inconfudible sello concejil.

Al lado de las Escuelas municipales, simultáneamente, aparecen las de los gremios - tan fomentados ya en la época romana-, estructuraciones sociales corporativas, que organizan, con mejor sentido de la dignidad del hombre, a los individuos integrantes de las unidades laborales, artesanía y profesiones; sobre cuyo antecedente, que ensambla toda la Edad Media económica, tanto se viene ahora investigando y escribiendo, a la vez que el viejo módulo trata de ser reproducido y adecuado a las grandes realizaciones sociales de algunos Estados modernos. Absolutamente nada había en ellos que alentase esas broncas lucubraciones de nuestras sociedades, ese mentís torvo de la humanidad ilustrada y pretenciosa, esa expresión condenatoria del hombre y de sus valores sustanciales que significan el proletariado, ei gregarismo o el hombre-masa.

La reglamentación del Gremio era en verdad minuciosa, mejor dicho, escrupulosa, pero con noble rendimiento a una tradición, a un abolorio patriarcal, cuya vitalidad no decrecía. Nada había en la norma sencilla, en el rito o ceremonia, que fuese rosa impensada, inestable o no abonada por la propia razón de vida del ente organizado, que evolucionabá consecuentemente, sin desgarraduras ni anegamientos pasionales... Las escuelas municipales y gremiales mueren, pero no las mata la prudencia ni la bondad de los hombres, sino su orgullo y su locura. Ambas prestaron servicios inapreciables y establecieron cauces de vida no bien recorridos aún por la tarea investigadora, echando 
los cimientos de un nuevo, extraordinario poder cultural: la Universidad. Firme y en pie el espíritu corporativo, eje social de la Edad Media, sobre él montaría con hálito pleno de Cristiandad este más alto monumento de la enseñanza, que como su inspirador, llevaría inherente la facultas hic et ubique docendi. $Y^{T}$ de este modo, como se ha afirmado, las Universidades no lo eran de un territorio determinado ni para unos determinados individuos, sino de la Cristiandad entera, que fruto fueron deI Cristianismo.

- Y bien: Las Universidades, los Colegios mayores universitarios, tienen un precedente que los abona en los Estudios concejiles, en las Escuelas gremiales, en cuyos senos se descubren las vocaciones mejores que es preciso aprovechar y recibir, para su verificación completa, en el aglutinante supremo de las altas corporaciones docentes. A éstas seguirá concurriendo innúmero tropel de estudiantes pobres, "vagabundos y goliardos", creadores de toda una rama singularmente pintoresca de la poesía neolatina, "los Cantos de los vagabundos", que sonríen picarescos en los aires adustos del Medioevo, duermen en ventas y hosterías, solazan ambientes cortesanos y señoriales, regocijan, hasta estremecer de gozo, las barbas de plata del señor Abad, penetran irresponsables en los retiros monásticos, en los que el estudiante aventurero encontraba beneplácito fácil para. su albergue y socorro. Pero a estos estudiantes pobres, como norma no involucrada, los sostiene la caridad, a veces hija del Gremio, los protege la jurisdicción episcopal, los aloja y garantiza. el Concejo... que el Concejo va unido a las empresas de cultura y afirmación de esta Edad maravillosa y difícil, en la que las personas, las instituciones y los pueblos, se definen con recia personalidad.

III.-FELIPE IV Y LOS PROYECTOS FRUSTRADOS DEL SIGLO XIX

Los Reyes Católicos mantienen y renuevan el esplendor de la enseñanza, de auspicio concejil, y el buen clima cultural subsiste revivificado durante los reinados de Carlos I y Felipe II. En este tiempo se produce la reacción sabia y oportuna de la 
Iglesia y brilla nuestro inigualado Siglo de Oro. Funciona en Madrid el famoso Colegio de la Villa, en el que cursa sus estudios Miguel de Cervantes, bajo la autoridad docente de López de Hoyos. En 1560 se ordena, para Galicia, que los padres que no envíen sus hijos a las escuelas sufran destierro, y se prohibe puedan ser alcaldes quienes no sepan leer ni escribir (Carrillo Guerrero).

Pero la línea se ha roto. Comienzan a mal-lucir los colorines intrascendentes, los espejismos fútiles. Sobre la personalidad de nuestros reyes cae el aluvión de las privanzas. Felipe IV, calamidad coronada, limita la existencia de Estudios públicos de Gramática a las ciudades y villas donde haya corregidor, y solamente un estudio en cada lugar, cercenando la iniciativa y la fundación privadas, los estímulos concejiles. Por la Pragmática de 10 de febrero de 1623 prohibe se hagan fundaciones particulares de colegios con menos de 300 ducados de renta, y caso de fundarse sería únicamente "en las dichas ciudades y villas".

El Concejo actúa, no obstante, cuando una ocasión reclama su presencia. Ha amanecido en Roma, con San José de Calasanz, toda una cruzada de la enseñanza. Las Escuelas Pias encarnan el más puro sentido de la caridad e interpretan, sin parangón, el espíritu docente de la Iglesia; ellas buscarán al niño pobre del arrabal perdido y pestilente, lo alimentarán y lo regenerarán. El joven Calasanz, caballero andante de la Iglesia docente, ha escuchado la voz del Cielo y "José, fué a Roma", repitiéndose con él el signo y el milagro, al tomar el mando y la partida de donde los tomaron los primeros y los mejores, porque Roma es término y principio. Pero Calasanz, que es español, ha de traer su nueva, anhelantemente, a España.

Hemos dicho que con él - con Calasanz- alumbra toda una nueva era de la pedagogía; se forma, con ambición más depurada, la pedagogía social. Entonces habrá en España un poder camino del olvido a la postergación, un poder humilde que ya apenas recuerda la gloria de su pretérito; un poder, sin embargo, que no puede sucumbir jamás so pena sucumban con él ia sociedad y el Estado: el Municipio. Y el Municipio español es el que recibe a. Calasanz y a sus hombres. En 1638 establecen 
los Escolapios un colegio en Guisona. Muere „San José en 1648 y aquel centro no se había consolidado. Años después, un vecindario, por medio de su' Concejo, tiende el anhelo y los brazos y los Escolapios afincan ya definitivamente en el solar patrio del fundador, creando el Colegio de Moyá, en 1682, "según las bases acordadas con su Municipion (Lasalde). Un colegio en el que se darían las primeras letras, Latinidad y Humanidades, es decir, la primera y segunda enseñanzas. Lo mismo ocurriría poco después en Barbastro y en otras poblaciones. In'troducida inicialmente en España por la mano del Concejo, la Escuela Pía, orgullo de la Cristiandad, prodigará su simiente. de exquisita calidad docente por los ámbitos de la Península, izando en la capital de España los pabellones regios de San Antón y San Fernando, a los que va unida, especialmente al primero, toda importante vicisitud del Madrid castizo, popular y cortesano.

En un noble marco concejil, lleno de preocupaciones edilicias, lograron su fecundidad y renombre numerosas. Universidades españolas, perlas que fueron y orgullo de nuestras doradas comunidades: Alcalá, Lucena, Sahagún, Baeza, Orihuela, Almagro, Burgo de Osma, Estella, Vich, etc..., en cuyos patios y claustros, hoy arrumbados o en el olvido, "estaban al poste", junto a las viejas columnas los viejos maestros. También sucumbirán pronto. A medida que se fué desconociendo la fuerte razón de vida de la institución local se fueron abandonando supremos intereses de la colectividad y de la patria; las innovaciones "desfasadas" y los alégres cánticos de "la política" sonaron a cosa de artificio; todo lo que de ésta dimanaba parecía un mero préstamo fugaz.

Con el siglo xix llegan para la enseñanza local los intentos, pero, puede decirse, que nada más que los intentos; ellos se esfuman en medio de la más estruendosa palabrería de la Historia. Las Cortes de Cádiz aprueban, en 1821, un plan de estudios que comprende un sistema de escuelas denominadas $U n i$ versidades provinciales, germen - se ha dicho- de los modernos Institutos de Segunda Enseñanza. El proyecto no pasó de ser... un proyecto. Poco después -1825- se publica el "Reglamento regulador de las Escuelas de Latinidad y Colegios de 
Humanidades", que limitaba el número de estos centros «a las ciudades y villas que fuesen capital de provincia o cabezas de partidon. Tampoco surtió los efectos deseados, porque el Gobierno, tan largo en palabras, fué, como de costumbre, muy corto en hechos, y el nuevo plan sucumbió por falta de recursos y asistencias.

En 1836, el Duque de Rivas reprodujo el plan de las Cortes de 1821, creando establecimientos de enseñanza secundaria, distinguiendo las materias que debían constituir la educación general, de las meramente preparatorias para las Facultades. $\mathrm{Y}$ a este fin estableció Institutos elementales para la primera e Institutos superiores para la segunda. Este plan dejó de regir bien pronto; y aunque tampoco tenía vigencia el de 1821, sin embargo, fundándose en lo que consignaba aquél, "la Dirección General de Estudios" acometió la empresa de dotar a las provincias de Institutos de Segunda Enseñanza. El celo de algunos jefes políticos bastó para poner en movimiento a varias Diputaciones provinciales; el interés local continuó y así nacieron los Institutos que hoy existen en España o la mayor parte de ellos (Samper).

El mecanismo para la creación de los Institutos en esta época -según el autor últimamente citado- era el siguiente: Una Corporación o varios vecinos, como padres de familia, dirigían al Ayuntamiento o a la Diputación provincial una solicitud en la que, describiendo el atraso intelectual del país y los males que a las familias resultaban de separar de su lado a los niños cuando más necesarios les cran los cuidados paternales, pedían el establecimiento de un Instituto literario... Estas solicitudes, las más de las veces valor entendido con las Diputaciones y Ayuntamientos, eran acogidas, ampliadas y robustecidas, bajo ia acción de los jefes políticos, por dichas corporaciones e informadas por la autoridad provincial se dirigían al Ministerio de la Gobernación. Este las pasaba a la Dirección de Estudios, donde se formaba un expediente, cuyo término, por lo general, era una Real Orden creando el Instituto pedido.

A partir de 1847 existieron Institutos provinciales y locales, según que fueran sostenidos con fondos de la provincia o de 
la localidad: o de alguna fundación particular. Los había de primera y de segunda clase, con cinco años de enseñanza los primeros y cuatro los segundos, "distinción que procedía de la falta de fondos que impedía a varios de estos centros sostener el gasto de todos los estudios integrantes de la enseñanza secundaria" (Ibid). La Ley de Instrucción pública de 9 de septiembre de 1857 conservó las denominaciones expresadas y creó una nueva: los Institutos de tercera clase, categoría dependiente de la importancia de las poblaciones donde estuvieran establecidos. Fueron de primera categoría los de Madrid; de segunda, los de capitales de provincia y pueblos donde existiese Universidad, y de tercera los de las demás poblaciones.

Resalta cómo en estos momentos legislativos sobre educación - a los que faltó profundidad política, sentido de la finanza pública y verdadera información histórica, nacional y extranjera-, juegan un papel decisivo los organismos de la Administración local, aunque faltos de toda eficaz asistencia y comprensión por parte de los altos poderes públicos. Teóricamente, con muy pobre expresión y densidad prácticas, la preocupación social docente "asoma" por esta misma época. El Real Decreto de 17 de agosto de 1901 reorganiza los Institutos de Segunda Enseñanza, llamándoles. "Generales y Técnicos", y atribuyéndoles; además de los estudios de Bachillerato, los de las enseñanzas técnicas del Magisterio, Agricultura, Industria y Comercio, Bellas Artes y Artes industriales, con las clases nocturnas para obreros. En el preámbulo se denunciaba la marcha retardada de España con relación a otros países en la reforma y extensión de la enseñanza secundaria y se afirmaba que "el número de alumnos de Bachillerato aumenta en relación con el progreso de la cultura patrian... Hoy diríamos las cosas de otra forma: "Es precisa y muy urgente una enseñanza media - con fin en sí misma- para todos los españoles", a fin de que, sin sonrojarnos, podamos exclamar de nuevo, con Jovellanos, "que España fué la primera nación del mundo sabion.

Por la Real Orden de 27 de septiembre del mismo año "se pretende" mantener la existencia de los Institutos locales, confirmando a los catedráticos en sus puestos y asimilándoles en 
- sueldo a los de los provinciales; pero "descargando" en las Corporaciones locales o "populares" - como se decía- la financiación de aquellos y los aumentos previstos en la dotación del profesorado. ¿Comentarios?... ¿Para qué ? La fórmula de celiminación" era bien conocida y "la manera" muy propia de nuestra política liberal que solía poner una vela a Dios en el texto y otra al diablo en el espíritu, porque lo poco bueno que había, lejos de verse fortalecido, desapareció súbitamente como si, en efecto, "se lo hubiera llevado el diablo".

(Continuará)

Florentino Agustín Díez 